\title{
NEUROPSYCHOLOGICAL TESTS AND DRIVING IN DEMENTIA: A REVIEW OF THE RECENT LITERATURE
}

\author{
Marcia Thereza Silva*1, Jerson Laks ${ }^{2}$, Eliasz Engelhardt ${ }^{3}$ \\ Trabalho realizado pelo Centro para Alzheimer e outros Transtornos Mentais na Velhice - Instituto de Psiquiatria do Rio de Janeiro IPUB/ Universidade Federal do \\ Rio de Janeiro - UFRJ, Rio de Janeiro, RJ
}

\author{
*Correspondência: \\ Rua Fernando Osório, n 35 \\ - apto. 802 - Flamengo \\ Rio de Janeiro - RJ \\ CEP: 22230-040 \\ marciather@gmail.com
}

\begin{abstract}
SUMMARY
INTRODUction. Neuropsychological tests measure several aspects of cognition and are useful to evaluate elderly drivers with cognitive impairment. However, there is no consensus on a standard battery of tests that could accurately predict safe driving.

Овлестіve. The aim of this study is to review specific neuropsychological measures that may be useful to predict driving competence of demented individuals.

Method. To address neuropsychological tests used for dementia and the ability to drive, the authors searched for the keywords dementia, Alzheimer's, drive, driver, drivers, driving, tests, neuropsychological, and assessment, in Medline, PubMed, ISI and SciELO databases seeking articles from 2000 to 2008. Results. From 131 articles, 27 met the inclusion criteria. Porteus Maze, Clock drawing, Trail B, UFOV and NAB Tests were found to be the most relevant neuropsychological measures for the evaluation of fitness to drive.

Conclusion. Porteus Maze, Clock Drawing, Trail B, UFOV and NAB tests highlight visuospatial attention demands and/ or executive function. Those and other visuospatial and executive measures may be useful to predict driving competence of demented individuals.
\end{abstract}

KEY words: Dementia. Alzheimer. Driving. Neuropsychology. Aged.

\section{INTRODUCTION}

Preserved motor, perceptual, and cognitive functions are necessary for driving competence. Impairment in such areas affects the ability to drive and may cause accidents and fatal crashes. The risk of motor vehicle crashes for individuals with cognitive decline was first reported in $1967^{1}$. Dementia is a well recognized risk factor for unsafe driving ${ }^{2}$, although some early-demented individuals retain driving capacity during the initial stages of disease ${ }^{3,4}$. In general, subjects with dementia are poorer drivers than cognitively normal people, and increasing attention has been given to driving capacity and cognitive impairment. Crash risk is proportional to the severity of dementia ${ }^{5}$. The problem, however, consists in estimating fitness to drive in persons with mild dementia. Physicians are constantly faced by situations in which they are asked to decide on whether the elderly should give up driving. This is a key issue in clinical practice with the elderly, since it affects the freedom to circulate and also some aspects of self-esteem of people who have always been independent.
A growing body of literature supports the utility of neuropsychological assessment to predict driving competence of elderly with early-stage cognitive decline ${ }^{6}$. Neuropsychological testing provides a useful instrument for diagnosis and prognosis in geriatric assessment ${ }^{7}$. Because of the increasing number of elderly at risk for driving impairment, the consensus on objective tests for driving assessment is critical. Relevance of neuropsychological measures in the evaluation of fitness to drive has not yet been established ${ }^{2}$, nor is a 'Test Stand Battery' predictive of safe driving capacity available. Also, there is no consensus by investigators and professionals on whether old people with mild dementia should be prohibited to drive. The aim of this study is to review the evidence of specific neuropsychological measures that may be useful to predict driving competence of demented individuals.

\section{Methods}

The authors conducted a review of the literature on neuropsychological measures and drivers with Dementia by searching

1. Médica Psiquiatra. Mestrado pela Universidade Federal do Rio de Janeiro - UFRJ, Rio de Janeiro, RJ

2. Doutorado em Medicina e Psiquiatria pela Universidade Federal do Rio de Janeiro - UFRJ, Professor Adjunto da Faculdade de Ciências Médicas da Universidade Estadual do Rio de Janeiro - UERJ, Coordenador do Centro para Doença de ALzheimer e outros Transtornos Mentais na Velhice do Instituto de Psiquiatria da UFRJ, Rio de Janeiro, RJ

3. Professor Titular-Instituto de Neurologia Deolindo Couto e Coordenador do Setor de Neurologia Cognitiva e do Comportamento do Instituto de Neurologia da Universidade Federal do Rio de Janeiro - UFRJ, Rio de Janeiro, RJ 
Medline, SciELO, PubMed and ISI databases for articles from 2000 to 2008. Keywords used in combination were (neuropsychological and drive), (tests and driving), (driving and dementia), (driver and dementia), (Alzheimer and driver), (neuropsychological and driving), (assessment and driver), (driving and Alzheimer), (drive and dementia) and (dementia and drivers). Studies published in peer-reviewed journals that correlated driving performance with neuropsychological tests in demented drivers were included in this review. Studies with subjects aged 60 years or more presenting questionable dementia and/ or well defined cognitive loss were also included. Reports were excluded if they did not emphasize dementia with neuropsychological measures and ability to drive, if criteria of dementia were not described. Case studies, letters, comments, case reports and unpublished studies were not included.

\section{Results}

Search of literature yielded 27 studies that met criteria for inclusion out of 131 articles (26 studies were not about dementia; 49 studies did not emphasize neuropsychological measures; 22 articles were neither on dementia nor on neuropsychological measures; 3 studies were letters and 4 articles were not on driving competence). Studies disclosed conflicting results on cognitive factors and tests related to driving impairment among aged drivers with early dementia. Papers from 2000 to 2008, excluding review articles, are shown in table 1.

A number of prospective and review studies have examined scores on the MMSE in relation to driving competence ${ }^{8-15}$. Literature has yielded variable results. Some papers showed correlation between MMSE and driving competence ${ }^{11-15}$, while other results showed MMSE scores that did not reflect ability to drive ${ }^{8-13}$.

Specific tests with visuospatial and executive/ attention tests demands demonstrate correlation with driving competence ${ }^{2,12,16-19}$. Porteus Maze appears as a predictor of driving ability ${ }^{2,20}$. Ott et al. ${ }^{2}$ evaluated the ability to drive in subjects with possible dementia and mild dementia with standard neuropsychological tests: Porteus Maze, Controlled Oral Word Association, Clock Drawing, and Trail Making Test (TMT) - Part B ${ }^{21}$. Results showed that Porteus Maze performance and Trail B time were correlated with driving scores, but Porteus Maze was the only significant test to evaluate driving capacity. However, performance on the TMT has been significantly associated with ability to drive $e^{8,14,19-26}$, especially Trail B, which evaluates executive function. In particular, Frankston et al. ${ }^{6}$ studied 29 individuals (13 with mild dementia) comparing TMT and a variant of it, the Color Trails Test ${ }^{27}$ (CTT). Results showed that both tools are useful and provide similar information regarding road test outcome. A study by Brown et al. ${ }^{18}$ showed the correlation between road test performance and scores on Driving Scenes Test of the new Neuropsychological Assessment Battery ${ }^{28}$ (NAB). Participants included 31 individuals with diagnosis of very mild dementia and 24 healthy elderly. NAB tests appeared to have ecological validity for on-road driving ability in very mildly demented individuals. Whelihan et al. ${ }^{22}$ also found a strong relationship between visual attention and executive tests and on-road test performance, but not with other neuropsychological measures. They examined 46 older persons with mild cognitive decline using several measures, including general (e.g. MMSE), visuospatial (e.g. Visual Form
Discrimination Test $^{29}$ ), executive/attention (e.g. Useful Field of View ${ }^{30,31}$ (UFOV), TMT and Porteus Maze), language (e.g. Generative Naming ${ }^{32}$ ), and learning/memory measures (Brief Visual Memory Test ${ }^{33}$ ). Results showed consistent correlation between road test performance and executive and visual attention demands. Other studies found a strong correlation between UFOV and ability to drive ${ }^{14,17,18,34}$. Correlation between Clock Drawing Test and fitness to drive was demonstrated in some studies $^{23,35,36}$ and they all mentioned the Clock Drawing as an efficient instrument. Grace et al. ${ }^{20}$ compared driving performance in Alzheimer's and Parkinson's patients using Rey- Osterrieth Complex Figure ${ }^{37}$ (ROCF), Trail B, Hopkins Verbal List Learning Test $^{38}$ (HVLT) and specific motor symptoms. According to the authors, a major finding of this study was that driving impairment for both patient groups was related to performance on ROCF and Trail B measures, which are involved with executive and visuospatial functions. However, ROCF may not predict ability to drive ${ }^{26}$.

Some reviews investigated the role of neuropsychological measures and driving ability in mildly demented drivers ${ }^{8,39,40-42}$. They evaluated studies over the last 30 years, alerting about inconsistent results involving neuropsychological measures and driving competence. However, there is evidence that performance of executive and visual attention tasks was related to on-road tests of driving capacity $2,6,8,13,16-19,43-45$.

The British Psychological Society has stated, "no one test, or sets of tests, can as yet be recommended for off-road assessment"46 and the American Academy of Neurology (AAN) recommends that elderly with possible Alzheimer's disease, who have a total CDR score of 0.5 must be submitted to a driving evaluation ${ }^{39}$.

\section{Discussion}

The purpose of this review was to examine the effectiveness of neuropsychological evaluations to test driving competence. The period studied comprised the eight years of this decade. We decided to review only the most recent studies and describe some that showed direct correlation between specific neuropsychological measures and ability to drive of demented elderly, since there were already a number of systematic reviews of previous studies on the issue.

Studies investigating the relationship between driving and neuropsychological tests among the elderly and mildly demented populations have yielded contradictory results. The Mini-Mental State Examination (MMSE) is one of the most frequently administered cognitive screening tools to investigate impairment of elderly and their ability to drive ${ }^{47}$. In general, most articles agree that MMSE may fail to predict competence to drive in elderly with early cognitive decline ${ }^{39}$, probably because MMSE focuses mainly on orientation, language, and memory omitting the other domains of cognitive functioning important for driving competence. As such the, MMSE did not predict future crashes or traffic violations $s^{9,10,43}$.

Visual attention/ perception and executive demands are related to driving impairment $8,13,16-19,44,45$. Porteus Maze is a brief, nonverbal test that yields information to assess the ability to plan and change problem solving approaches ${ }^{25}$, and appears to be a predictor of driving ability ${ }^{2,20}$. NAB tests incorporate several aspects of visual attention including working memory, 
Table 1 - Studies of Neuropsychological tests and drivers with Dementia (2000 - 2008)

\begin{tabular}{|c|c|c|c|c|}
\hline Study & Diagnoses & $\mathrm{N}$ & Measures & Results \\
\hline Frankston et al., 2007 & $\begin{array}{l}\text { mild dementia/ CVD/ } \\
\text { encephalopathy/ PD/ } \\
\text { syncope/ head injury }\end{array}$ & 29 & $\begin{array}{l}\text { Trail } A \text { and } B, \text { MMSE, } \\
\text { CTT1 and } 2\end{array}$ & $\begin{array}{l}\text { Trail } A: U=53.00, p<0.05 ; C T T-1: U=59.00 \\
p<0.05 ; \text { Trail } B: U=77.00, p=0.07 ; C T T-2: \\
U=56.00, p=0.06 ; \text { MMSE: } U=44.00 ; p<0.05\end{array}$ \\
\hline Ott et al., 2006 & $\begin{array}{l}\text { probable; possible DA/ } \\
\text { Controls }\end{array}$ & 133 & NTB & $\begin{array}{l}\text { Highest correlations: Trail A }(r=.50 p<.0005) \text {; } \\
\text { Trail B }(r=.48, p<.0005) \text {; HVLT1 }(r=-.47 \\
\qquad p<.0005) \text { for the entire sample }\end{array}$ \\
\hline
\end{tabular}

Grace et al., 2005

mild $\mathrm{AD} / \mathrm{PD} /$ controls

questionable dementia/ Controls

probable $\mathrm{AD} /$ controls

170

very mild dementia/

Controls

Ott et al., 2003

Schanke et al., 2000 very mild dementia/ mild dementia/ controls questionable dementia

dementia/ brain damage
63

55

ROCF, Trail B, NAB, HVLT, Trail A, MNT,

Finger tapping

46

MMSE,DRS,BSI,UFOV,

AMNART, WCST, Action

Fluency, Trail A and B,

Ruff Figural Fluency,

MNT, Generative

Naming, BVMT-R,

Letter Cancellation Test,

BVMT - Copy, VFDT

LTIT; NTB

NAB, Road Test

67

Porteus Maze errors,

Porteus Maze time,

Clock Drawing, Trail B, COWA

NTB
Identifying AD at-risk drivers: Trail B, ROCF presence and HVLT - discrimination $(p<.01)$; Trail A; HVLT learning or delay; NAB; Mazes and Finger tapping $(p<.001)$

Highest correlations: Maze Navigation Time $(r .52, p<.01)$ and UFOV-I $(r=.61, p<.01)$ Maze Navigation time entered the analysis with a classification accuracy of $80 \%$ (Wilks lambda $=0.69$; chi-square $=11.6$, $p=.0001$ )

Trail B $(p<0.0001)$; AVLT $r(p<0.0001)$; UFOV $(p<0.0001)$; CS $(p=0.0007)$; JLO $(p=0.0379)$ as predictors of LTIT

Correlation between NAB and Road Test: $(r(55)=-.55, p<.01)$

Porteus Maze drawing time emerged accounting $41 \%$ of the variance in ratings

Trail B, SDMT and Block Design $(p<0.001)$; Trail A ( $p<0.002)$; Stroop Test $(p=0.382)$; Digit Span $(p=0.429)$

$\mathrm{AD}=$ Alzheimers Disease; CVD = Cerebrovascular Disease; PD = Parkinsons Disease; CTT = Color Trails Test; MMSE = Mini Mental State Exam; ROCF = Rey-Osterrieth Complex Figure; DRS = Dementia Rating Scale; HVLT = Hopkins Verbal List Learning Test; NAB = Neuropsychological Assessment Battery; BSI = Brief Symptom Inventory; UFOV = Useful Field of View; AMNART = American version of the National Adult Reading Test; WCST $=$ Wisconsin Card Sorting Test; BVMT-R = Brief Visual Memory Test - Revised; VFDT =

Visual Form Discrimination Test; Maze Navigation Test = MNT; NTB = Neuropsychological Test Battery; LTIT = Landmark and traffic sign identification; DC = driving competence; COWA = Controlled Oral Word Association; CI = Confidence Interval; JLO = Judgment of Line Orientation; CS = Contrast Sensitivity; SDMT = Serial Digit Modalities Test

visual scanning, selective attention and attention to detail ${ }^{22}$. Correlation was found between road-test performance and scores on Driving Scenes Test of the new NAB ${ }^{28}$. UFOV, an executive/ attention test covers the ability to focus and the speed of visual attention. Some studies found a strong correlation between UFOV and ability to drive ${ }^{13,17,18,34}$. In particular, UFOV is a now commercially available resource that seems to be promising as a predictor of driving ability.

The American Medical Association's (AMA) document, Physician's Guide to Assessing and Counseling Older Drivers ${ }^{48}$ recommends the Clock Drawing Test and Trail Making Test-Part $B$ as tools for the evaluation of drivers, rather than exclusively for the evaluation of dementia severity. The validity of the Clock Drawing Test was demonstrated in some studies $23,35,36$. However, a recent systematic review disclosed that this is not sufficiently justified ${ }^{41}$, although all Clock Drawing Test scoring methods appear as an efficient instrument to evaluate fitness to drive ${ }^{36}$.

Our review found that no single test is sensitive enough to predict ability to drive. Performance of tests on visuospatial demands may identify fitness to drive in early dementia. Tasks that assess executive processing, particularly those that also have visuomotor demands may be useful to identify at-risk drivers with early dementia. Other cognitive measures, including 
memory scores, did not adequately predict driving performance in demented persons.

Porteus Maze, Clock Drawing, Trail B, UFOV and NAB tests correlate significantly with on-road driving performance. In contrast, MMSE is a rather limited instrument to estimate driving competence. MMSE scores do not include perception, and motor evaluations which are domains of cognitive functioning important for driving competence. Tasks that assess visuospatial attention and executive demands such as computer-administered tests should be the focus of future simulator studies ${ }^{49}$. Such assessments may have good ecological validity to evaluate driving performance.

Our study includes a small number of articles, which may have limited our findings.

\section{ConcLusion}

Driving competence is a key feature in daily clinical practice with elderly patients, regardless of the physician's specialization. Usually, the physician has to decide whether the patient is still able to drive and is also asked by the family which measures should be taken in this regard. Among other results, this review shows that the MMSE score is not reliable for making this decision, and that specific visuospatial and executive tests should be performed.

\section{Conflict of interest: none}

\section{Resumo}

TESTES NEUROPSICOLÓGICOS E DIREÇÃo NA DEMÊNCIA: UMA REVISÃo DA LITERATURA RECENTE

INTRODUÇÃO. Testes neuropsicológicos aferem diversos aspectos de cognição e são úteis para avaliar motoristas idosos que apresentam déficits cognitivos. Entretanto, ainda não existe consenso sobre uma bateria de testes capaz de apurar com eficiência os riscos de dirigir. Objetivo. O objetivo deste estudo foi revisar medidas neuropsicológicas específicas, capazes de prognosticar competência para dirigir em indivíduos com demência.

MÉTODos. Para identificar testes neuropsicológicos que predizem habilidade para dirigir, os autores intersectaram as palavras-chave: demência, Alzheimer, dirigir, condutor, condutores, direção, testes, neuropsicológicos e avaliação nas bases Medline, Pubmed, ISI e Scielo, buscando artigos entre os anos 2000 e 2008.

Resultados. Dos 131 artigos encontrados, 27 deles apresentaram critérios de inclusão. Os testes: Labirinto de Porteus, Desenho do Relógio, Trilhas - parte B, 'UFOV' (Campo de Visão Útil) e 'NAB' (Bateria de Avaliação Neuropsicológica) demonstraram-se como as mais relevantes medidas neuropsicológicas que avaliam aptidão para dirigir.

Conclusão. Os testes: Labirinto de Porteus, Desenho do Relógio, Trilhas - parte B, UFOV e NAB demandam atenção vísuo-espacial e/ ou função executiva. Estas e outras medidas de desempenho executivo e função vísuo-espacial possivelmente exercem importante papel na predição de competência para dirigir em idosos com demência. [Rev Assoc Med Bras 2009; 55(4): 484-8]

Unitermos: Demência. Alzheimer. Direção. Neuropsicologia. Idosos.

\section{References}

1. Walter JA. Cardiovascular disease, aging, and traffic accidents. J Chronic Dis. 1967;20:615-20.

2. Ott BR, Heindel WC, Whelihan WM, Caron MD, Piatt AL, DiCarlo MA. Maze Test performance and reported driving ability in early dementia. J Geriatric Neurol. 2003;16:151-5.

3. Hunt L, Morris JC, Edwards D, Wilson BS. Driving performance in persons with mild senile dementia of the Alzheimer type. J Am Geriatr Soc. 1993;41:747-53.

4. Rizzo M, Reinach S, McGehee D, Dawson J. Simulated car crashes and crash predictors in drivers with Alzheimer's disease. Archiv Neurol. 1997;54:545-51.

5. Australian Society for Geriatric Medicine. Position Statement No. 11: driving and dementia. Available from: http://www.asgm.org.au/pdfdocs/positionstatements/PositionStatement No11.pdf.

6. Elkin-Frankston S, Lebowitz BK, Kapust LR, Hollis AM, OConnor MG. The use of the Color Trails Test in the assessment of driver competence: Preliminary report of a culture-fair instrument. Arch Clin Neuropsychol. 2007;22:631-5.

7. The Status of Neuropsychological Testing in Psychogeriatrics in the Year 2000. Int Psychogeriatr. 1999;11:347-9.

8. Brown LB, Ott BR. Driving and dementia: a review of the literature. J Geriatr Psychiatry Neurol. 2004;17:232-40.

9. Trobe JD, Waller PF, Cook-Flannagan CA, Teshima SM, Bieliauskas LA. Crashes and violations among drivers with Alzheimer's disease. Arch Neurol. 1996;53:411-6.

10. Fox GK, Bowden SC, Bashford GM, Smith DS. Alzheimer's disease and driving: Prediction and assessment of driving competence. J Am Geriatr Soc. 1997;45:949-53.

11. Fitten LJ, Perryman KM, Wilkinson CJ, Little RJ, Burns MM, Pachana N, et al. Alzheimer and vascular dementias and driving: a prospective road and laboratory study. JAMA. 1995;273: 1360-5.

12. Lesikar SE, Gallo JJ, Rebok GW, Keyl PM. Prospective study of brief neuropsychological measures to assess crash risk in older primary care patients. J Am Board Fam Pract. 2002;15:11-9.

13. Uc EY, Rizzo M, Anderson SW, Shi Q, Dawson JD. Driver landmark and traffic sign identification in early Alzheimer's disease. J Neurol Neurosurg Psychiatry. 2005;76;764-8.

14. Paccalin M, Bouche G, Barc-Pain S, Merlet-Chicoine I, Nedelec C, Gil R. Automobile driving among patients with dementia. Survey in the Poitou-Charentes region. Presse Med. 2005; Jul 23,24:919-22.

15. Adler G, Kuskowsky M. Driving cessation in older men with dementia. Alzheimer Dis Assoc Disord. 2003;17:68-71.

16. Ball, K. Visual attention problems as a predictor of vehicle crashes in older drivers. Invest Ophtalmol Vis Sci. 1993;34:3110-23.

17. Whelihan WM, DiCarlo MA, Paul RH. The relationship of neuropsychological functioning to driving competence in older persons with early cognitive decline. Arch Clin Neuropsychol. 2005;20:217-22.

18. Brown LB, Stern RA, Cahn-Weiner DA, Rogers B, Messer MA, Lannon MC et al. Driving Scenes test of the Neuropsychological Assessment Battery (NAB) and on-road driving performance in aging and very mild dementia. Arch Clin Neuropsychol. 2005;20:209-15.

19. Reger MA, Welsh RK, Watson GS, Cholerton B, Baker LD, Craft S. The relationship between neuropsychological functioning and driving ability in dementia: a meta-analysis. Neuropsychology. 2004;18:85-93.

20. Grace J, Amick MM, DAbreu A, Festa EK, Heindel WC, Ott BR. Neuropsychological deficits associated with driving performance in Parkinson's and Alzheimer's disease. J Int Neuropsychol Soc. 2005;11:766-75.

21. Lezak MD. Neuropsychological assessment. 3rd ed. New York: Oxford University Press; 1995.

22. Whelihan WM, Di Carlo MA, Comparetto T, Donovan M. The maze navigation test: normative data and preliminary psychometric properties. Poster presented at the Annual Meeting of the National Academy of Neuropsychology. Chicago; 2001.

23. De Raedt R, Ponjaert-Kristoffersen I. Short cognitive/neuropsychological test battery for first-tier fitness-to-drive assessment of older adults. Clin Neuropsychol. 2001;15:329-36.

24. Szlyk JP, Myers L, Zhang Y, Wetzel L, Shapiro R. Development and assessment of a neuropsychological battery to aid predicting driving performance. J Rehabil Res Dev. 2002;39:483-96.

25. Schanke AK, Sundet K. Comprehensive driving assessment: neuropsychological testing and on-road evaluation of brain injured patients. Scand J Psychol. 2000;41:113-21.

26. Ott BR, Festa EK, Amick MM, Grace J, Davis JD, Heindel WC. Computerized maze navigation and on-road performance by drivers with dementia. J Geriatr Psychiatry Neurol. 2008;21:18-25.

27. D' Elia LF, Satz P, Uchiyama CL, White T. Color Trails Test (CTT). Psychological Assessment Resources Inc; 1994.

28. Stern RA, White T. Neuropsychological Assessment Battery (NAB). Lutz: Psychological Assessment Resources, Inc.; 1994. 
29. Benton AL, Hamsher KS, Varney NR, Spreen O. Contributions to neuropsychological assessment. New York: Oxford University Press; 1983.

30. Ball K, Roenker D. Useful field of view. 1998 San Antonio: The Psychological Corporation; 1998.

31. The useful field of view test: a new technique for evaluating age-related declines in visual function. J Am Optometry Assoc. 1993; 64:71-79.

32. Benton AL, Hamsher KS. Multilingual aphasia examination. Iowa: AJA Associares; 1989.

33. Benedict R. Brief-Visual Memory Test: revised. 1997 Odessa: Psychological Assessment Resources; 1997.

34. Myers RS, Ball KK, Kalina TD, Roth DL, Goode KT. Relation of useful field of view and other screening tests to on-road driving performance. Percept Mot Skills. 2000;91:279-90.

35. De Raedt R, Ponjaert-Kristoffersen I. Short cognitive/neuropsychological test battery for first-tier fitness-to-drive assessment of older adults. Clin Neuropsychol. 2001;15:329-36.

36. Freund B, Gravenstein S, Ferris R, Burke B. Drawing clocks and driving cars. J Gen Intern Med. 2005;20:240-4. Rehabilitation Research and Development. 2002;3:483-96.

37. Stern RA, Javorsky DJ, Singer EA, Harris NG, Somerville JA, Duke LM, et al. Boston Qualitative Scoring System of the Trey-Osterreith Complex Figure. 1999 Odessa: Psychological Assessment Resources; 1999

38. Benedict R. Hopkins Verbal Learning Test - Revised. 1998 Lutz: Psychological Assessment Resources; 1998.

39. Adler G, Rottunda S, Dysken M. The older driver with dementia: An updated literature review. J Safety Res. 2005;36:399-407.

40. Breen DA, Breen DP, Moore JW, Breen PA, O'Neill D. Driving and dementia. BMJ. 2007;334:1365-9.

41. Molnar FJ, Patel A, Marshall SC, Man-Son-Hing M, Wilson KG. Clinical utility of office-based cognitive predictors of fitness to drive in persons with dementia: a systematic review. J Am Geriatr Soc. 2006;54:1809-24.
42. Man-Son-Hing M, Marshall SC, Molnar FJ, Wilson KG. Systematic review of driving risk and the efficacy of compensatory strategies in persons with dementia. J Am Geriatr Soc. 2007;55:878-84.

43. Brown LB, Ott BR, Papandonatos GD, Sui Y, Ready RE, Morris JC. Prediction of on-road driving performance in patients with early Alzheimer's disease. J Am Geriatr Soc. 2005;53:94-8.

44. Ott BR, Anthony D, Papandonatos GD, DAbreu A, Burock J, Curtin A, et al. Clinician assessment of the driving competence of patients with dementia. J Am Geriatr Soc. 2005;53:829-33.

45. Szlyk JP, Myers L, Zhang Y, Wetzel L, Shapiro R. Development and assessment of a neuropsychological battery to aid in predicting driving performance. J Rehabil Res Dev. 2002;39:483-96.

46. British Psychological Society Multi-Disciplinary Working Party on Acquired Neuropsychological Deficits and Fitness to Drive. Fitness to drive and cognition. Leicester: BPS; 1999. Available from: http://www.bps.org.uk.

47. Folstein MF, Folstein SE, Mc Hugh PR. Minimental state: a practical method for grading the cognitive state of patients for the clinician. J Psychiatr Res. 1975;12:189-98.

48. Carr DB. Physician's guide to assessing and counseling older drivers. Ann Emerg Med. 2004:43:746-7.

49. Innes CR, Jones RD, Dalrymple-Alford JC, Hayes S, Hollobon S, Severinsen $J$, et al. Sensory- motor and cognitive tests predict driving ability of persons with brain disorders. J Neurol Sci. 2007;260:188-98.

Artigo recebido: 16/06/08 Aceito para publicação: 04/11/08 